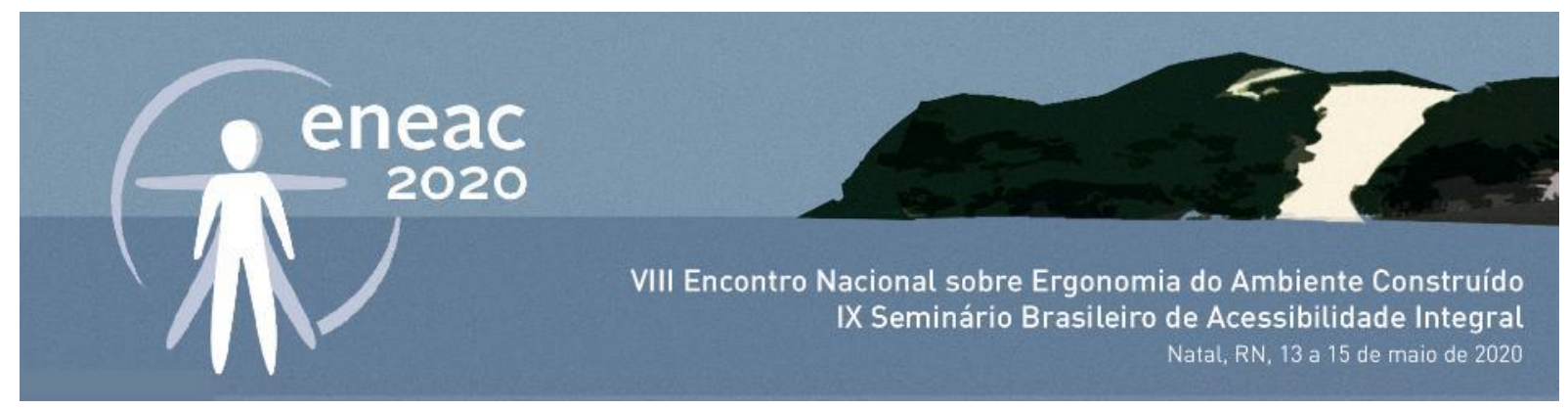

\title{
Projetando paraciclos: uso de metodologia centrada no usuário como suporte para um processo de projeto colaborativo
}

\author{
Design bike racks: use of user-centered methodology as support for \\ a collaborative design process
}

DIOGO GOMES PEREIRA BATISTA

Arquiteto e Urbanista, Doutorando na Pós Graduação em Arquitetura e Urbanismo da UFPB, diogo.choia@gmail.com

BÁRBARA LAÍS FELIPE DE OLIVEIRA

Arquiteta e Urbanista, Doutoranda na Pós Graduação em Arquitetura e Urbanismo da UFPB, barbara.felipe@ufersa.edu.br

ERIKA FERREIRA MARINHO

Arquiteta e Urbanista, Mestranda na Pós Graduação em Arquitetura e Urbanismo da UFPB, erikamarinho.f@gmail.com

ANGELINA DIAS LEÃO COSTA

Arquiteta e Urbanista, Professora do Departamento de Arquitetura e Urbanismo da UFPB, angelinadlcosta@yahoo.com.br

\section{RESUMO}

A bicicleta é um veículo que gera uma série benefícios socioambientais e econômicos para a sociedade. O desenvolvimento de estruturas cicloviárias de qualidade serve como fomento e valorização do uso da bicicleta pela população, propagando assim os seus benefícios. Para tanto, é essencial um processo projetual que leve em consideração o usuário, através do uso de instrumentos colaborativos que promovam essa abordagem. $O$ objetivo do artigo é apresentar a experiência de aplicação de uma metodologia de design centrado no usuário, com ênfase no processo de inspiração para concepção de um produto. Para tanto, a metodologia tem como referência o Guia de Orientação para Desenvolvimento de Projetos - GODP (MERINO, 2016), com procedimentos que partem de uma pesquisa bibliográfica sobre a temática definida processos projetuais participativos e a concepção de paraciclos. Isso levou a geração de debates realizados a partir de uma disciplina de Pós-Graduação da Universidade Federal da Paraíba em João Pessoa-PB, onde ambientou-se a pesquisa de campo e aproximação com a comunidade universitária de ciclistas. Desse modo, foram desenvolvidas as etapas de geração de informações, prospecção e levantamento de dados, presentes na fase de "Inspiração" do GODP, considerando a temática de paraciclos. Os resultados apresentam um diagnóstico das 


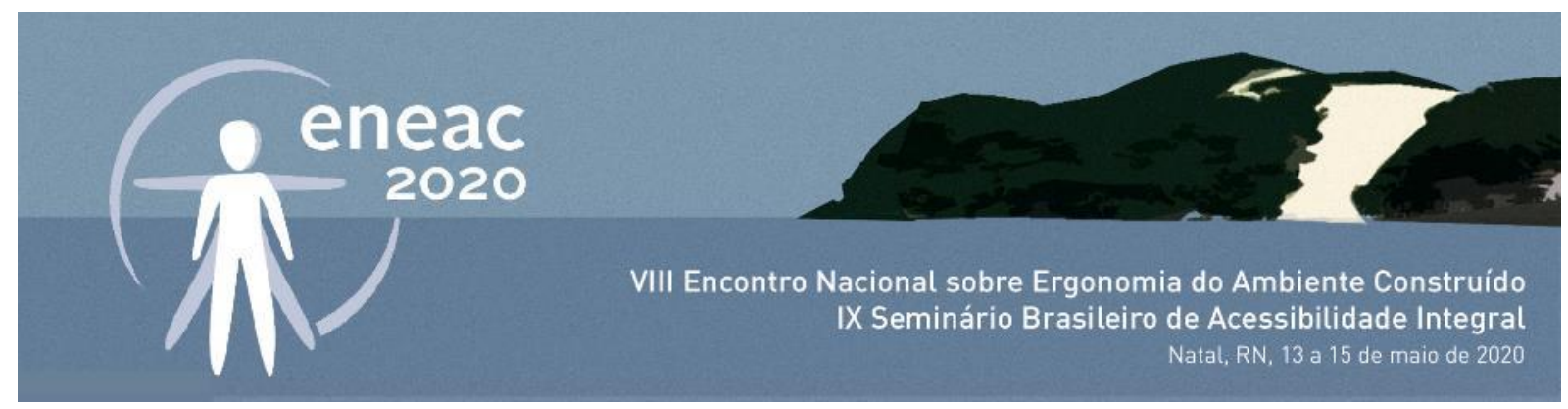

potencialidades, problemáticas e mapeamento da situação existente de paraciclos na UFPB, bem como, considerações a partir dos ciclistas como suporte para a concepção de paraciclos para o local.

PALAVRAS-CHAVE: ciclista, paraciclo, bicicleta, metodologia de projeto, campus universitário

\begin{abstract}
The bicycle is a vehicle that generates a series of socio-environmental and economic benefits for society. The development of quality bicycle structures serves to promote and enhance the use of bicycles by the population, thus spreading its benefits. For this, a design process that considers the user with collaborative instruments that promote this approach is essential. The objective of the article is to present the experience of applying a user-centered design methodology, with an emphasis on the process of inspiration to designing a product. For this purpose, the methodology is based on the Guidance for Project Development - GODP (MERINO, 2016), with procedures that start from bibliographic research on the theme defined participatory design processes and the design of bike racks. The generation of debates held based on a Post-Graduation course at the Federal University of Paraiba in João Pessoa-PB, where the field research and approximation with the university community of cyclists took place. In this way, the stages of information generation, prospecting, and data collection, present in the "Inspiration" phase of GODP, were developed, considering the theme of bike racks. The results present a diagnosis of the potentialities, problems, and mapping the existing situation of bike racks at $U F P B$, as well as considerations from cyclists as support for the design of bike racks for the place.
\end{abstract}

KEYWORDS: cyclist, bike racks, bicycle, design methodology, university campus

\title{
1 INTRODUÇÃO
}

O processo projetual, ora planejado, ora espontâneo ou intuitivo como a nossa linguagem, pode ser dinâmico ou até mesmo caótico, creem Lawson (2015) e Turnhout et al. (2017). Pesquisadores também dizem que é comum pensarmos em um processo projetual como sendo pré-planejado e altamente estruturado, mas na prática, projetistas atuam de modo mais fluido, o que Lawson (2015, p.2017) nominou de "atividade natural". Apesar de natural, Veloso e Elali (2014) e Lawson (2015) concordam que durante o processo projetivo é imprescindível a consideração do outro, bem como o uso de ferramentas colaborativas como forma de desenvolvimento das habilidades sociais para negociação, diminuição de tensão entre os atores e a apropriação do produto pelo usuário final.

As propostas de Design Thinking se inserem como um meio de olhar para o usuário em arquitetura, sendo assim, um processo que muitas vezes conduz o projetista a princípios de transformação, inovação e evolução outrora negligenciados. Segundo Merino (2016, p.7), "pensar em projeto centrado no usuário é colocar o usuário no centro de cada fase do desenvolvimento de um produto ou serviço". Aqui, busca-se compreender o projetar sob uma abordagem humanista, fruto de um trabalho colaborativo, de trocas, como parte de uma perspectiva multidisciplinar. É essencial inserir o usuário no processo de projetação como meio para obter ambientes construídos mais acessíveis, que considere suas reais necessidades, reduzindo assim a distância existente entre projetistas e os destinatários finais de seus projetos. Aí existem questões que objetivam, além de uma leitura das necessidades do destinatário final, uma experiência de projeto completa que englobe a análise das informações, testes, avaliação e planejamentos que se alinhem com o mundo real em todas as etapas. 


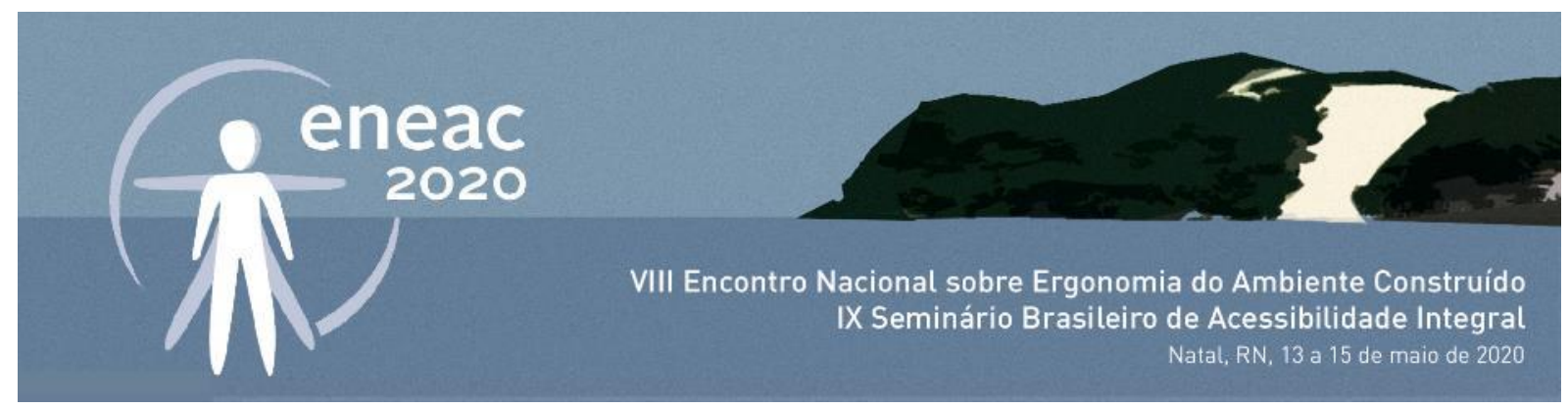

Merino (2016) afirma ainda que esse meio de projetação faz inferência aos aspectos sensoriais, cognitivos e motores dos usuários, bem como aos aspectos temporais e sociais. O projeto torna-se muito mais uma organização das informações sob diversas perspectivas do que uma criação. "O desafio está em identificar, levantar, compreender e converter as informações sobre o usuário" (ibid., 2016, p.8). Essa metodologia de projeto permite identificar as causas e efeitos dos problemas em projeto, auxiliando de forma satisfatória no desenvolvimento de produtos mais funcionais e inovadores. Para Melo e Abelheira (2015, p. 15) existe aí:

\begin{abstract}
[...] uma metodologia que aplica ferramentas do design para solucionar problemas complexos. Propõe o equilíbrio entre raciocínio associativo, que alavanca a inovação, e o pensamento analítico, que reduz os riscos. Posiciona as pessoas no centro do processo, do início ao fim, compreendendo a fundo suas necessidades. Requer uma liderança ímpar, com habilidade para criar soluções a partir da troca de ideias entre perfis totalmente distintos. (MELO; ABELHEIRA, 2015, p.15)
\end{abstract}

Durante $o$ ato de projetar é comum se defrontar com o desafio de lidar com uma grande quantidade de informações a respeito do lugar (contexto), das pessoas (usuários) e do objetivo de projeto almejado (produto) (MERINO, 2016). Nesse sentido, é importante desenvolver e reconhecer possíveis procedimentos metodológicos que auxiliem na resolução de desafios como o citado anteriormente. Esse artigo é fruto da experiência de reflexão teórica e prática desenvolvida no âmbito de uma disciplina de pós-graduação acerca de "metodologias e ferramentas de auxílio ao projeto com foco no usuário". O objetivo geral do artigo é apresentar a experiência de aplicação de uma metodologia de design centrado no usuário, com ênfase no processo de inspiração para concepção de um produto através do Guia de Orientação para Desenvolvimento de Projetos - GODP (MERINO, 2016). Para tanto, tem-se como objeto/produto a ser desenvolvido: paraciclos para possível implantação na Universidade Federal da Paraíba em João Pessoa/PB.

\title{
2 METODOLOGIA
}

Os procedimentos metodológicos realizados para esse trabalho fizeram parte das atividades desenvolvidas durante a disciplina intitulada "Qualidade e avaliação do ambiente construído" em seu módulo 2 "Metodologias e ferramentas de auxílio ao projeto com foco no usuário"; do Programa de Pós-Graduação em Arquitetura e Urbanismo da Universidade Federal da Paraíba (PPGAU/UFPB), ocorrida no segundo semestre de 2019. A turma contou com a participação de alunos e professores da área de Design e Arquitetura e Urbanismo.

Conforme o foco no usuário da disciplina, inicialmente foi realizada uma pesquisa bibliográfica sobre projetos participativos e colaborativos onde cada aluno escolheu um artigo, realizou fichamento e apresentou aos colegas. Como critérios de restrição da pesquisa, esses artigos deveriam estar publicados em periódicos qualificados pela CAPES, datados entre os anos de 2015 e 2019. Além disso, foram realizadas apresentações pelos professores sobre métodos de projeto centrado no usuário, como base para as discussões. Diante do contexto do espaço institucional universitário e considerando uma situação-problema: a demanda existente de ciclistas no campus e a necessidade de mobiliário para estacionamento de bicicletas; o produto paraciclo foi escolhido como foco para o desenvolvimento do processo projetual teórico-prático. Desse modo, foi realizada uma nova revisão 


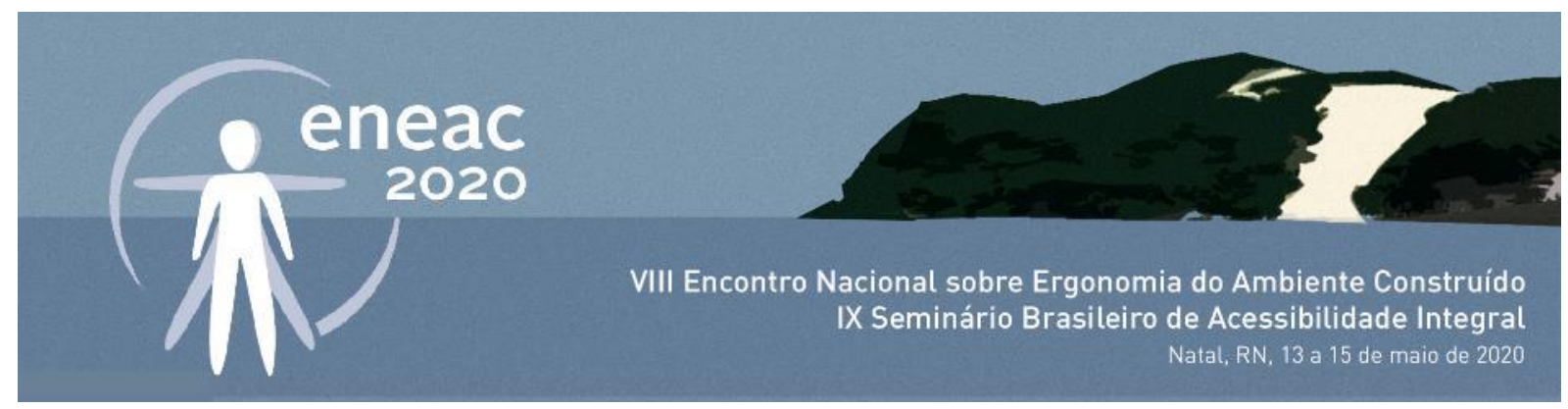

literária, conforme a dinâmica anteriormente apresentada, tratando especificamente da temática da infraestrutura cicloviária e dos usuários de bicicleta.

A partir da etapa teórica inicial, partiu-se para a aplicação de uma metodologia de design centrado no usuário a partir do Guia de Orientação para Desenvolvimento de Projetos com base em Merino (2016). Desse modo, foi realizada uma Pesquisa de Campo, onde foram realizadas visitas in loco, para registro e identificação de potencialidades e problemáticas através da técnica de Walkthrough que consiste em uma vivência no local de estudo através de um passeio a pé, onde são realizadas observações e avaliações relativas ao espaço e às atividades nele desempenhadas (RHEINGANTZ et al., 2009). Nesta etapa também foram realizadas entrevistas informais com usuários da comunidade universitária a fim de identificar as características relevantes a serem consideradas em um futuro projeto. Nesse artigo serão apresentados os resultados obtidos para a fase de Inspiração da referida metodologia que envolvem as etapas de Oportunidades, Prospecção e Levantamento de Dados.

\section{DESIGN THINKING NO ATO DE PROJETAR: O MÉTODO GODP}

A partir das diretrizes do Design Thinking, o método GODP - Guia de Orientação para Desenvolvimento de Projetos (MERINO, 2016), se apresenta como uma alternativa para a organização das literaturas de design e da compilação de metodologias diversas. O GODP foi desenvolvido a partir da contribuição de diversos autores para a estruturação e adaptação de uma metodologia que considere o maior número de aspectos para respostas de forma consciente e organizadas com ênfase no usuário do produto. É um processo cíclico, uma vez que há uma constante retroalimentação das informações, em que o usuário é o protagonista, buscando-se atendê-lo da forma mais completa possível, considerando o máximo de informações no processo, como objetivo final.

O GODP reserva 03 fases, as quais servirão para auxiliar no desenvolvimento do produto almejado. Dentro delas existem 08 etapas, com o objetivo de expor a coleta de informações direcionadas ao desenvolvimento da proposta, o desenvolvimento criativo, a execução projetual, a viabilização e verificação final do produto. Desse modo, têm-se as seguintes fases e etapas: Inspiração (etapas: -1 oportunidades; 0 prospecção e 1 levantamento de dados), Ideação (etapas: 2 organização e análise, 3 criação) e Implementação (etapas: 4 execução, 5 viabilização e 6 verificação final) (MERINO, 2016) (ver Figura 1). Além disso, esse método sugere um quadro modelo para preenchimento de informações de acordo com cada fase, servindo como um registro dinâmico de dados coletados para facilitar a leitura e inter-relações do conjunto de informações produzidos pelos membros do grupo envolvido com o processo de projeto (ver Figura 2). 


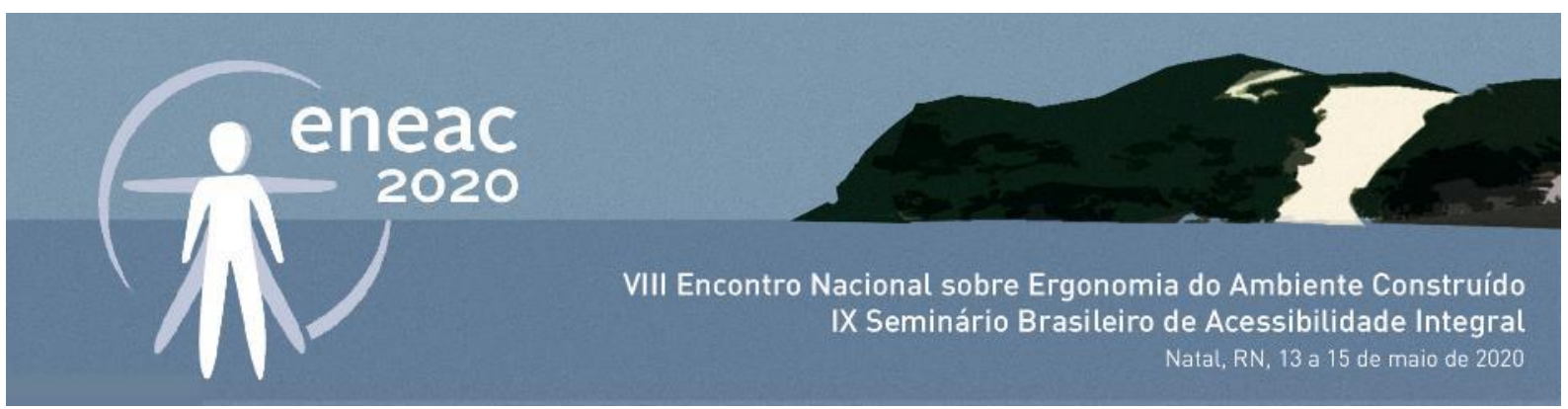

Figuras 1 e 2: Metodologia e quadro do GODP, respectivamente.

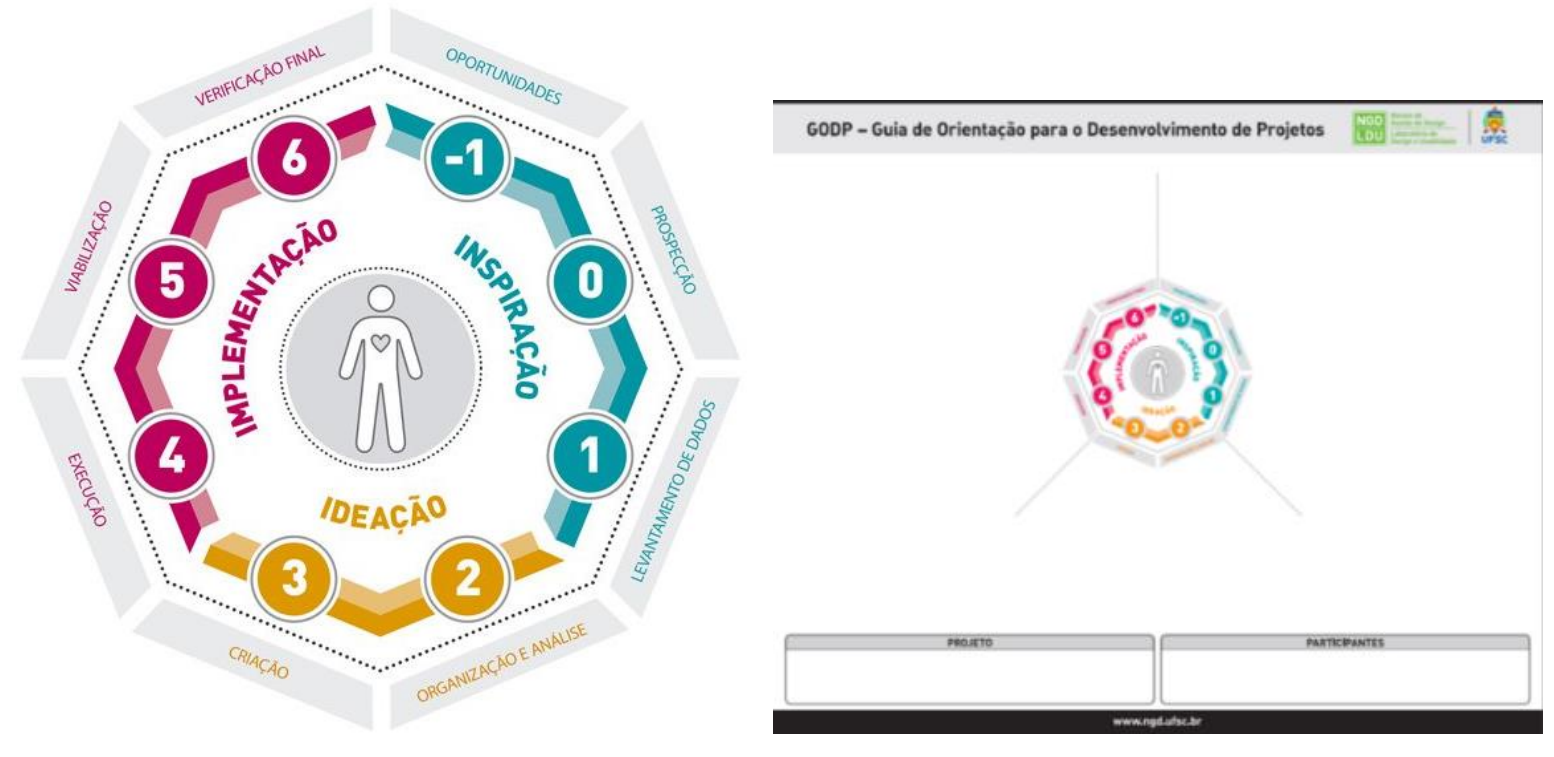

Fonte: NGD-LDU/UFSC, 2019.

Graficamente, as fases citadas, bem como as etapas, são representadas em uma curva que relaciona tempo, referências e o nível morfológico das realizações. O método é composto por 03 'blocos de referência' - Produto, Usuário e Contexto - que são a base para a escolha de técnicas e ferramentas para o desenvolvimento do projeto. A partir deles, observa-se qual o produto, pra quem é/quais serão os usuários e onde ele está inserido. Esta metodologia está descrita em um livreto, que contém uma breve apresentação, um guia construtivo, painel e demais instruções para a sua utilização (MERINO, 2016). Ela se propõe, em suma, a guiar o projetista por meio de marcos projetuais, permitindo agregar ferramentas ou técnicas que auxiliem na verificação e avaliação, etapa a etapa do trabalho, durante seu desenvolvimento.

\section{RESULTADOS}

A partir da pesquisa bibliográfica, onde foram consultados artigos de periódicos nacionais e internacionais, encontrou-se diversas abordagens sobre paraciclos em Universidades. Assim, depararam-se distintos estudos de caso, que contribuíram para o desenvolvimento de debates em sala de aula.

Um dos casos utilizados como referência foi o trabalho realizado por Khadem et al.(2019), no qual os autores apresentam um estudo destinado a identificar os melhores locais para implantação de paraciclos na Morgan State University, em Baltimore/EUA. Outro estudo que merece destaque foi o realizado por Rodrigues et al. (2015), que apresenta o processo de desenvolvimento do projeto de um parklet como solução para a implantação de paraciclo na Universidade Regional de Blumenau (FURB). Destaca-se também o trabalho de Heinen e Buehler (2019) que realiza uma revisão sistemática da literatura sobre estudos sobre estacionamento de bicicletas e identifica as lacunas 


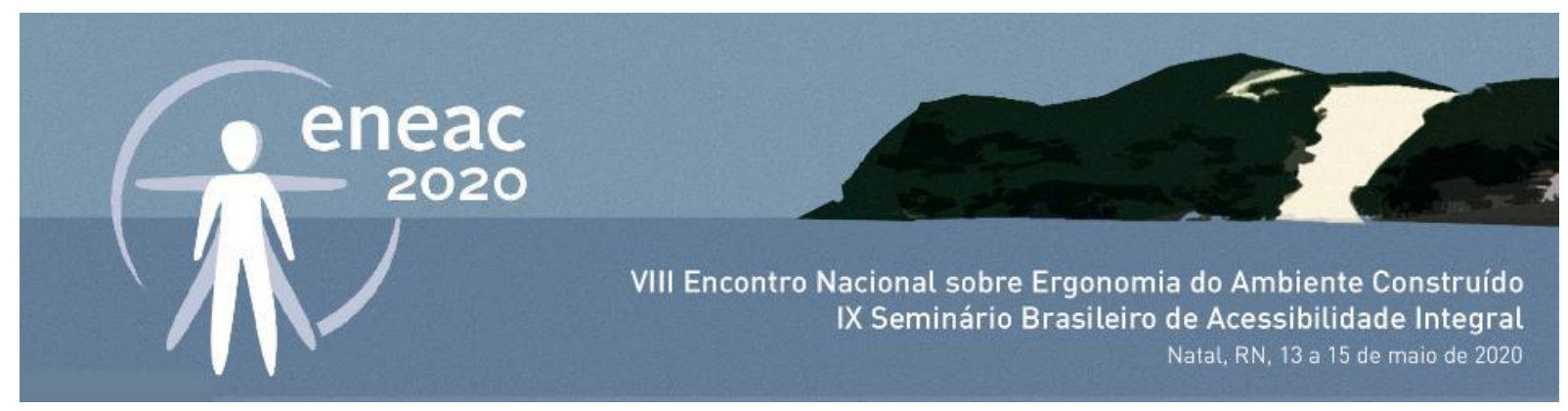

existentes na produção científica. Já como estudo local, o trabalho de Cevada (2015) trata da mobilidade cicloviária no campus I da UFPB, sendo fundamental para um contato de informações de base primária, como a localização de alguns paraciclos existentes no Campus I da UFPB na época do estudo; assim como, resultados de questionários realizados que permitiram identificar o perfil dos ciclistas do campus, informações sobre os fatores de influência de tráfego de veículos e pessoas na instituição.

O campus I da UFPB foi o local escolhido para ser universo de estudo das potencialidades e problemáticas sobre o uso e oferta de paraciclos. Essa instituição é um local que se configura como um polo gerador de viagens (PGV). Segundo o Departamento Nacional de Trânsito, os PGV podem ser caracterizados por empreendimentos de grande porte que produzem ou podem atrair um grande número de viagens. No entanto, podem trazer alguns reflexos negativos na circulação viária em seu entorno imediato quando não há um bom planejamento e infraestrutura adequada para os diferentes modos de transporte. Os deslocamentos na região dos PGV podem ser prejudicados, sobretudo em horários de pico de trânsito cotidiano, podendo agravar as condições de segurança de motoristas, pedestres e ciclistas. Por conta disso, se faz importante minimizar o impacto negativo no trânsito, principalmente devido ao excesso de transportes motorizados de uso individual, e priorizar os veículos mais sustentáveis, como é o caso da bicicleta. O espaço de uma Universidade, como é o caso do Campus I da UFPB, possibilita a sua utilização, uma vez que possui ruas planas, arborização e baixa velocidade de veículos motorizados, além de possuir uma grande demanda de deslocamentos de curta distância advindos dos bairros vizinhos como Castelo Branco e Bancários.

Já o paraciclo (produto escolhido a ser projetado) é um mobiliário urbano de suporte para estacionamento temporário de bicicletas e com a finalidade de salvaguardar esses veículos. Esse tipo de solução mostra-se essencial, uma vez que contribui para uma maior valorização e usufruto da bicicleta, potencializando a demanda de ciclistas, e que poderia ser ainda mais incentivada seguindo um plano amplo de mobilidade dentro do Campus. A bicicleta é um veículo não motorizado que gera uma série de benefícios não só para a saúde e bem estar do ciclista como para toda a sociedade em geral, uma vez que não gera emissões de poluentes, minimiza a geração de ruídos, ocupa menos espaço para deslocamento e estacionamento, gera economia e possui baixo custo, entre vários outros fatores que caracterizam esse modo de deslocamento como uma forma de transporte mais sustentável (ANDRADE et al.,2015).

Embora não existam ciclovias ou ciclofaixas que integrem o Campus I da Universidade Federal da Paraíba aos bairros circundantes e à cidade como um todo, há um grande número de ciclistas que utilizam a bicicleta como meio de transporte cotidiano e que enfrentam dificuldades para estacionar a bicicleta. Nesse contexto, e utilizando a metodologia de projeto centrada no usuário GODP, realizou-se um processo dinâmico de estudo preliminar para futuros projetos de Paraciclos a serem instalados no referido campus.

A aplicação do GODP foi iniciada pela etapa "-1: OPORTUNIDADES", onde foi realizada uma investigação de informações sobre o lugar, o público, os equipamentos existentes e sua situação, bem como a identificação de requisitos importantes a serem considerados em um futuro projeto de 


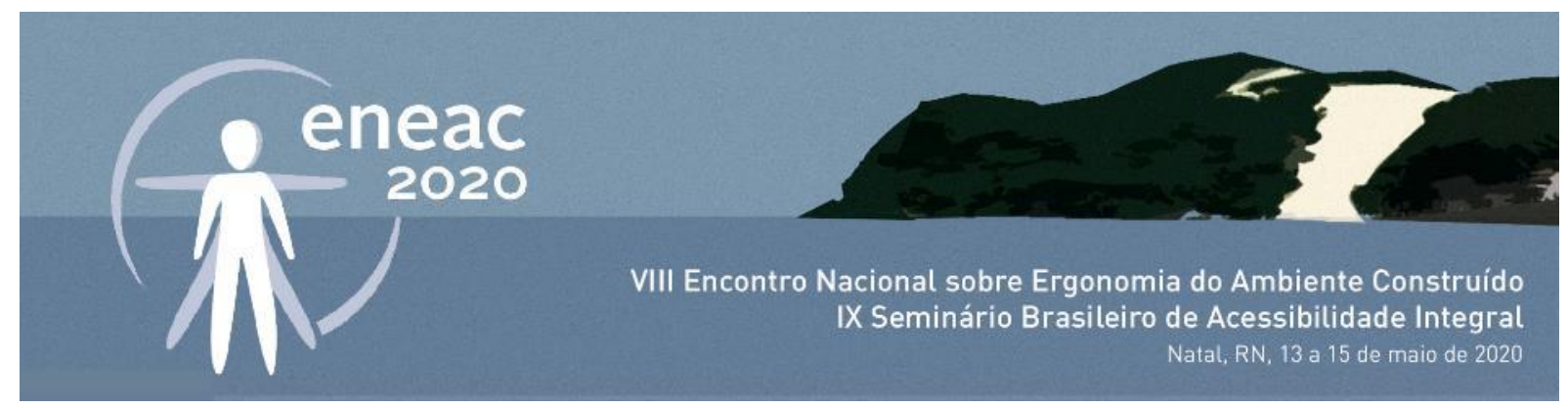

paraciclos. Nessa etapa foi observado que o paraciclo deve ser pautado nas premissas de que a bicicleta permite maior praticidade e rapidez nos deslocamentos internos à Universidade já que não há um transporte coletivo circular na instituição. Para a bicicleta, necessita-se de menor espaço para estacioná-la comparado a um carro. Por exemplo, no espaço de uma vaga para um automóvel, caberiam cerca de 8 vagas para bicicletas ou mais. Para tanto, o paraciclo é um mobiliário que confere mais segurança, suporte e integração para o estacionamento de bicicletas.

Na segunda etapa, denominada "O: PROSPECÇÃO", foram definidas algumas diretrizes tais como: o projeto do paraciclo deve ser baseado no desenho universal, atendendo a usuários de diferentes alturas, com mobilidade reduzida ou essas com deficiência, como também deve haver uma localização estratégica dos paraciclos, com instalação de uma maior quantidade em locais próximos à vestiários, que possam servir como uma parada de apoio, anterior ao destino final dos usuários. Nessa etapa também foram consideradas como informações importantes o mapeamento do perfil do ciclista da UFPB, utilizando como referência o questionário elaborado e aplicado por Cevada (2015). O Quadro 01 apresenta uma síntese desse mapeamento.

Quadro 1: Perfil do ciclista da UFPB.

\begin{tabular}{c|c}
\hline \multicolumn{2}{|c}{ PERFIL DO CICLISTA } \\
\hline GÊNERO & $\begin{array}{c}85 \% \text { - Masculino } \\
15 \% \text { - Feminino }\end{array}$ \\
\hline RENDA & Classe baixa (D) (90\%) e não possui veículo particular motorizado para fazer o percurso CASA \\
- UFPB - CASA
\end{tabular}

Fonte CEVADA, 2015. Adaptado pelos autores, 2019.

Na etapa denominada "1 - LEVANTAMENTO DE DADOS", foi feita uma Pesquisa de Campo através da técnica Walktrough, a fim de identificar, localizar e qualificar todos os paraciclos da UFPB. $O$ Walkthrough é bastante utilizado em avaliações de desempenho do ambiente construído e urbano, principalmente na Avaliação Pós Ocupação (APO), sendo muito útil para identificar qualidades e problemas dos lugares e do seu uso. Para tanto, a pesquisa é feita através de diferentes ferramentas de registro para reconhecimento do ambiente (como vídeos, fotografias e fichas de avaliação) (RHEINGANTZ et al., 2009). O passeio de bicicleta no local de estudo, também foi realizado devido a experiência de um dos autores como ciclista que usa a bicicleta para ir ao campus (ver figuras 3 e 4), o que se constituiu como um olhar diferenciado. Isso serve como uma forma de aprofundar o 


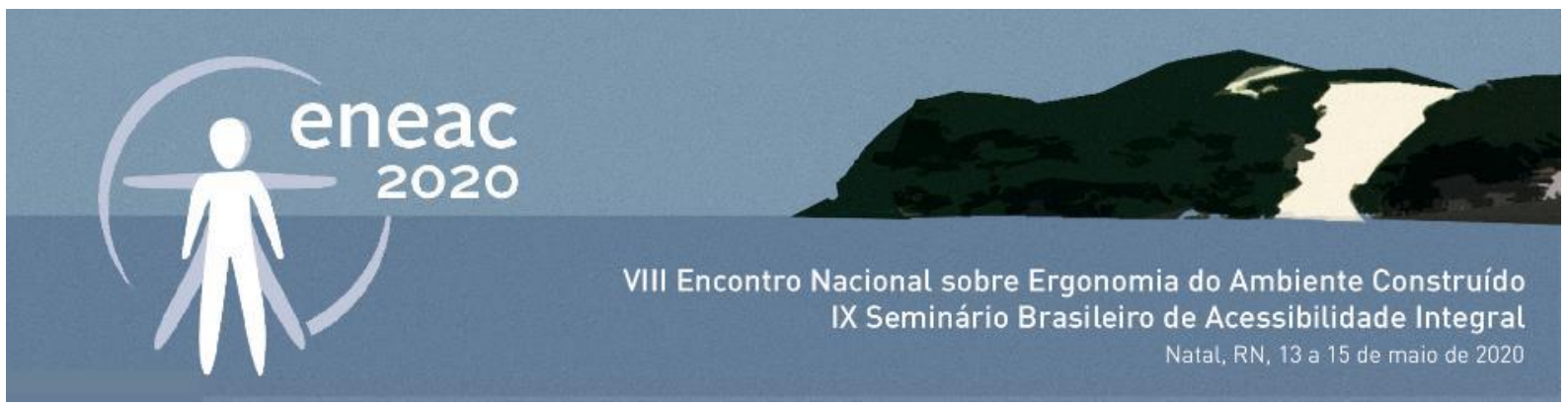

reconhecimento do local e aproximar o pesquisador do objeto de estudo, através da vivência e interação com o ambiente e as pessoas.

Figuras 3 e 4: Vivência e passeios de bicicleta nos locais de estudo.
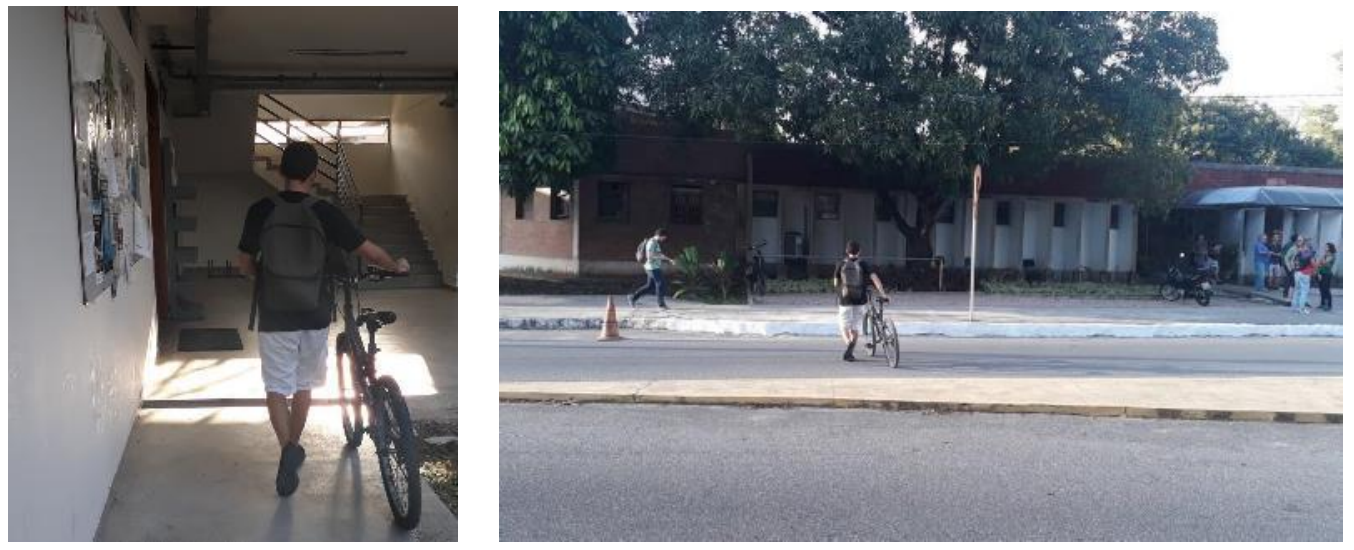

Fonte: Autores, 2019.

Durante a pesquisa de campo foram feitas ainda conversas informais com ciclistas no campus para uma melhor compreensão do ambiente construído e as relações de deslocamento de bicicleta no local estudado. Verificou-se a partir dessas entrevistas, a necessidade de incluir paraciclos em áreas que tenham infraestrutura de banheiros com vestiários, para o conforto dos usuários. Viu-se também a necessidade de locar os paraciclos em pontos estratégicos, próximo às entradas principais do campus e ao lado de estacionamentos de automóveis e motos, para facilitar sua visualização e identificação. Observou-se, ainda, a importância da boa iluminação para minimizar possíveis roubos de bicicletas.

Sobre a quantidade de paraciclos existentes no campus, foi observado que não havia dados atualizados sobre a infraestrutura cicloviária existente. Desse modo, os alunos da disciplina se dividiram em 3 grupos para reconhecer todo o espaço do Campus de maneira mais rápida, fazendo um levantamento in-loco, que serviu para mapear e quantificar e qualificar O mobiliário já instalado, considerando observações gerais da qualidade de uso, estado material do paraciclo e características de implantação. Também foram observados os componentes e design dos paraciclos. A Figura 5 apresenta a divisão para a pesquisa de campo do grupo, bem como a identificação dos principais centros e unidades administrativas da UFPB. Já a Figura 6 apresenta o mapeamento dos paraciclos existentes na universidade. 


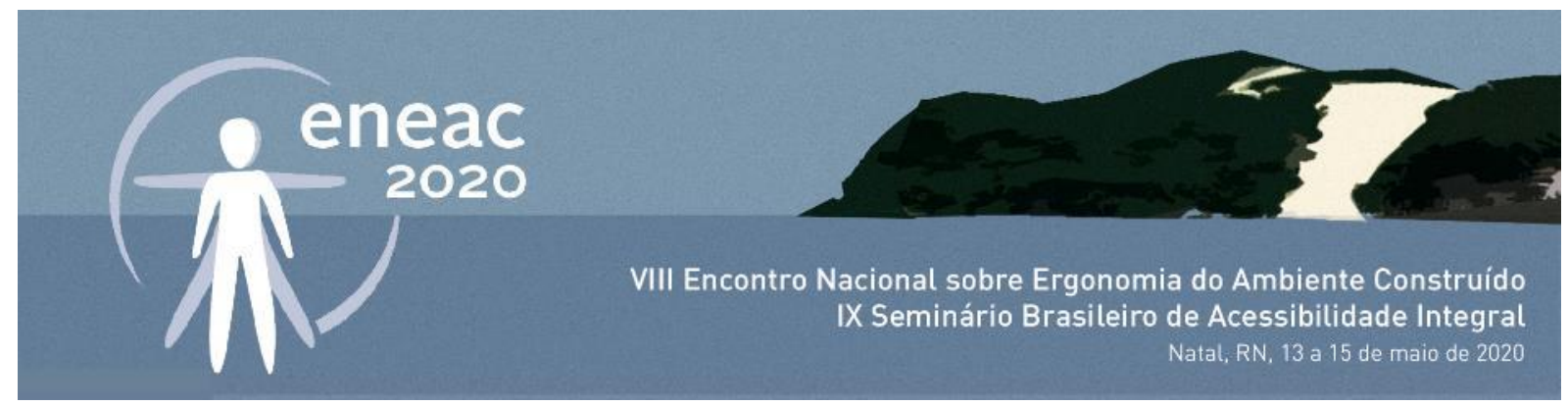

Figura 5: Divisão do Campus em 3 zonas para levantamento dos paraciclos existentes.

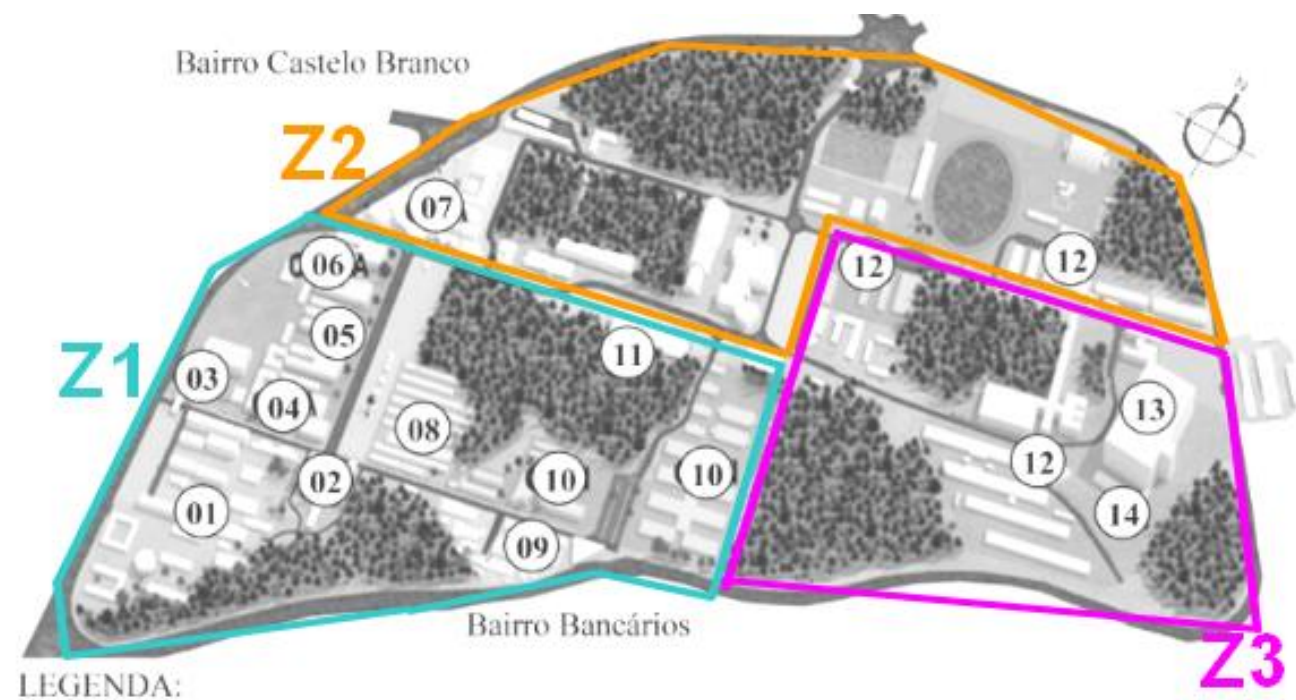

01. Centro de Tecnologia

02. Centro de Ciências Juridicas

03. Laboratório de Energia Solar

04. Centro de Cièncias Sociais Aplicadas

05. Centro de Educaçâo

06. Centro de Ciências Humanas, Letras e Artes

07. Centro de Ciencias, Turismo e Artes
08. Central de Aulas

09. Laboratório Ténológico Farmacêutico

10. Centro de Ciéncias Exatas e da Natureza

11. Biblioteca Central

12. Centro de Cièncias da Saúde

13. Hospital Universitário

14. Centro de Cièncias Médicas

Fonte: Cevada et al. (2015) adaptado pelos autores (2019).

Figura 6: Levantamento dos paraciclos existentes no campus

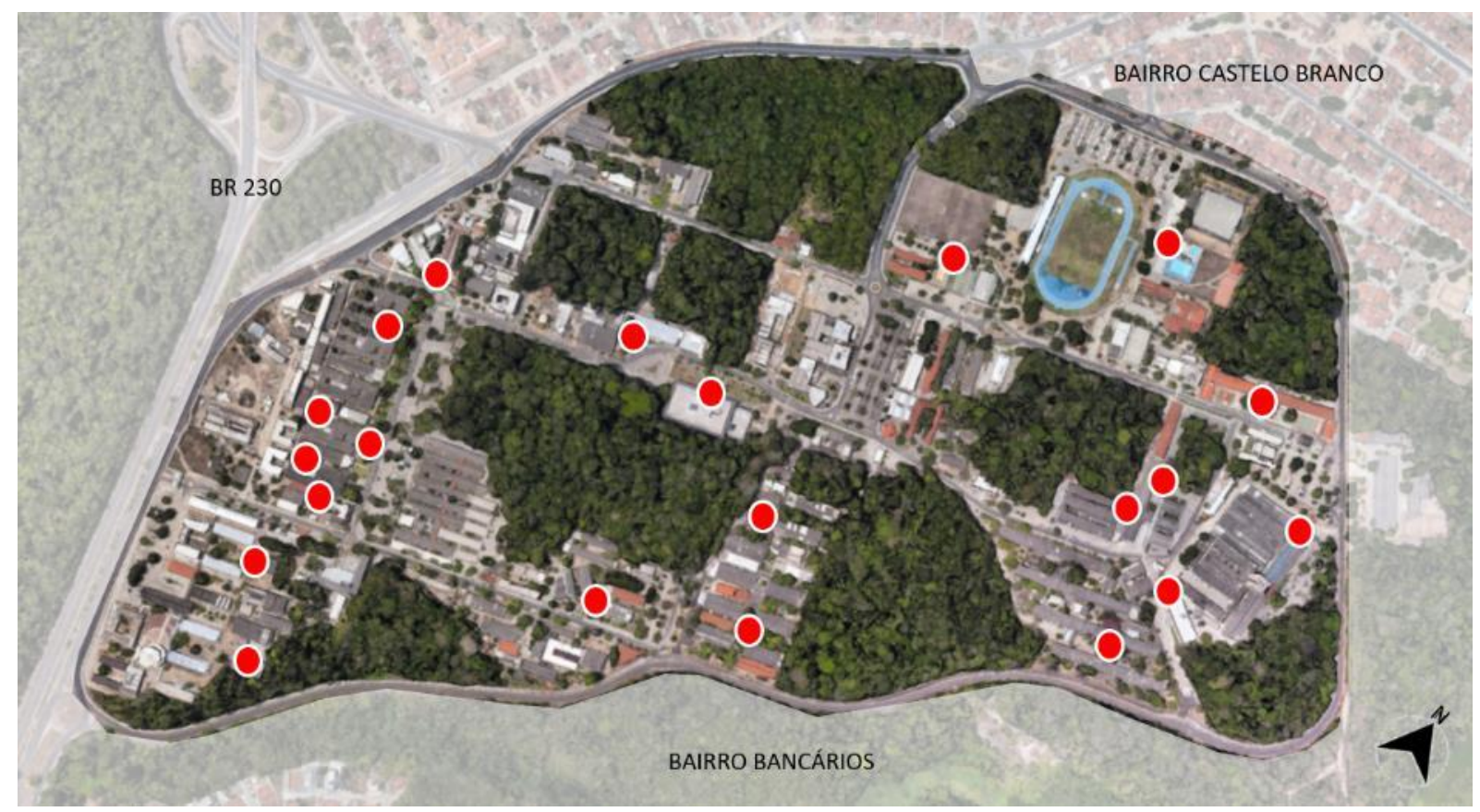

Fonte Autores, 2019, com base em imagem do Google Earth, 2019. 


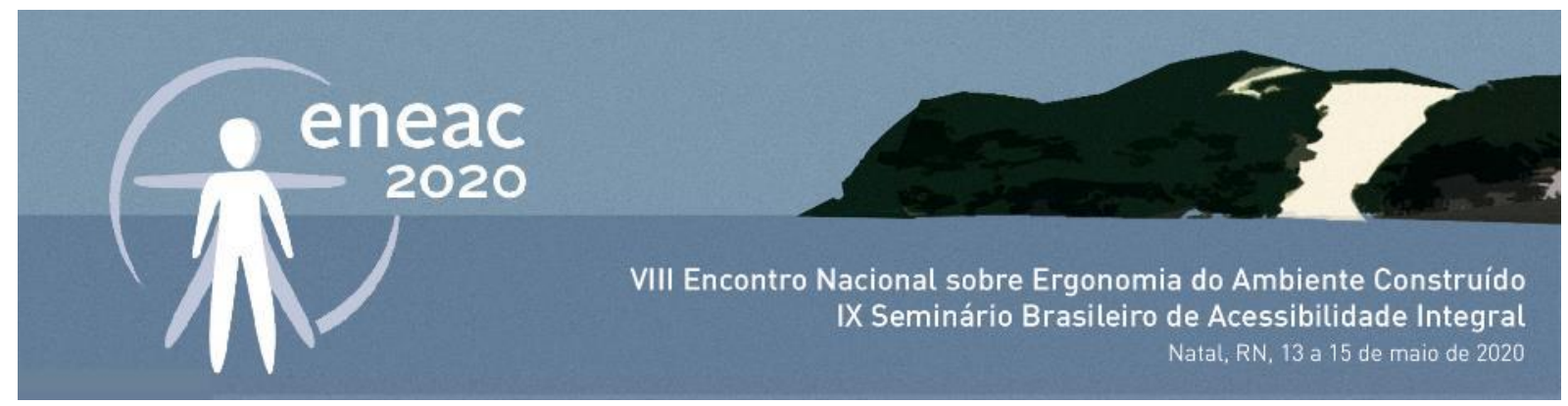

A partir desse mapeamento, pôde-se observar que após o levantamento de 2015 feito por cevada, que registrou apenas quatro paraciclos disponíveis em todo o campus, a quantidade desse mobiliário aumentou consideravelmente, sendo implantados em diversos novos locais, contabilizando 21 unidades no geral. Foram observados diferentes modelos de paraciclo, classificando-os em 03: o de piso, o vertical (ver figuras 7 e 8 ) e o de barra (ver figura 9 e 10).

Figuras 7 e 8 - Paraciclos de piso e vertical, respectivamente.
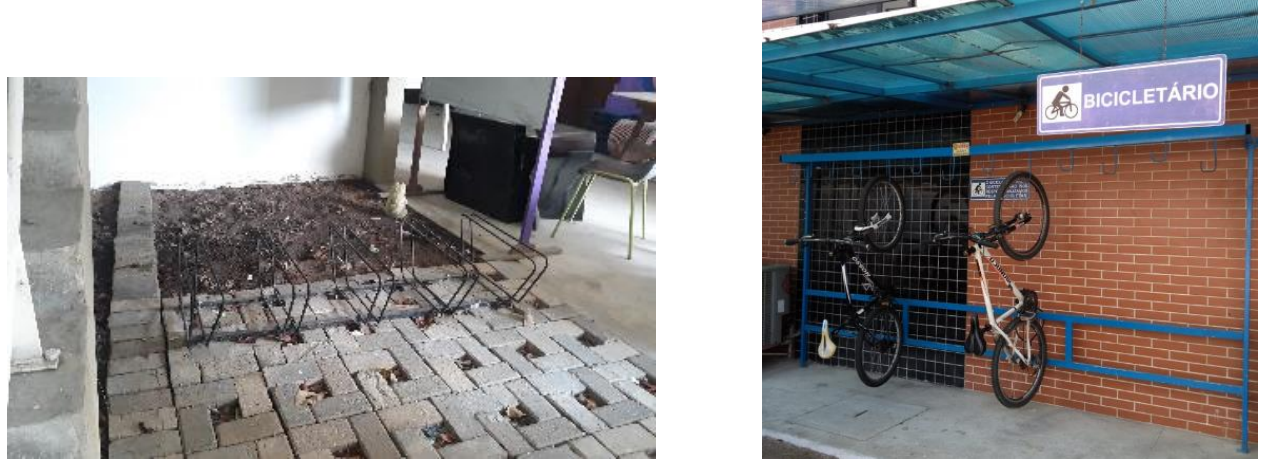

Fonte: Autores, 2019.

Figuras 9 e 10 - Paraciclos de barra encontrados no Campus.
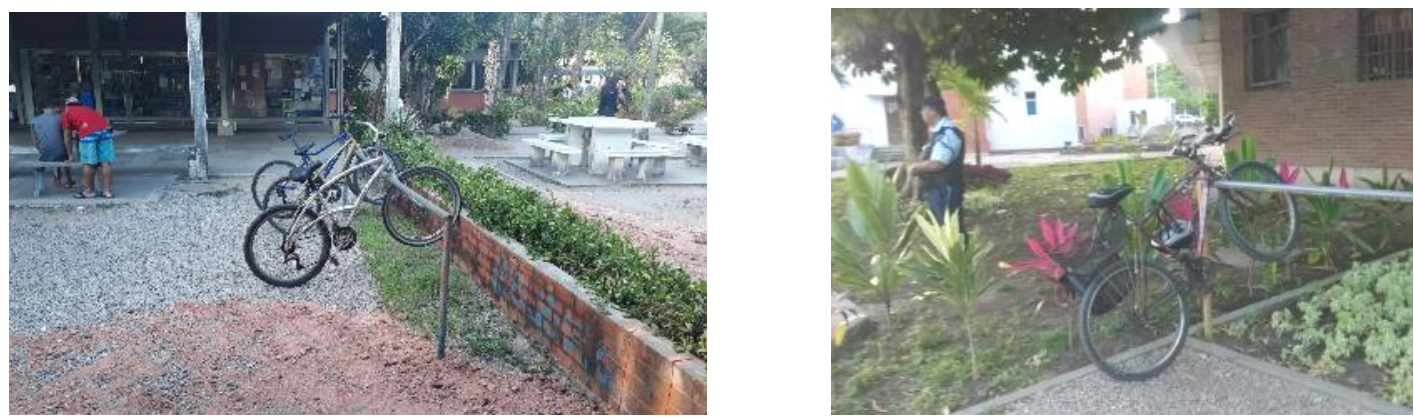

Fonte: Autores, 2019.

Verificou-se, no levantamento, que o maior número de paraciclos instalados, é de piso (mostrado anteriormente na Figura 07). Esse tipo, contudo, não é o mais aconselhável para uso, devido à avaria que pode ocasionar nas bicicletas, tais como: entortar e arranhar aros, danificar o câmbio traseiro das bicicletas e não conseguir acomodar bicicletas com aro menor ou maior que 26 polegadas, além de inconvenientes de desconforto ergonômico para prender a bicicleta (ACBC, 2012). Provavelmente devido a isso e ao fato de que alguns deles estavam locados em lugares de difícil acesso e de maneira que fica difícil estacionar uma bicicleta (ver figuras 11 e 12), mesmo existindo o mobiliário em quantidade considerável número, ainda foram encontradas diversas bicicletas estacionadas em locais inadequados, bem como paraciclo sem uso no momento da pesquisa (ver figuras 13 e 14). 


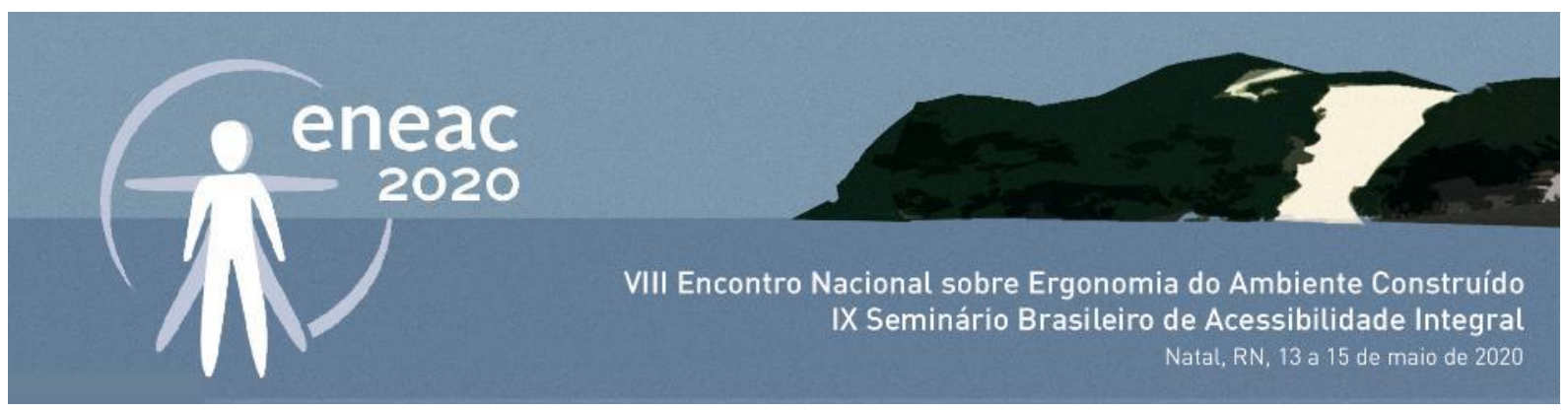

Figuras 11 e 12 - Paraciclos locados em lugares de difícil acesso
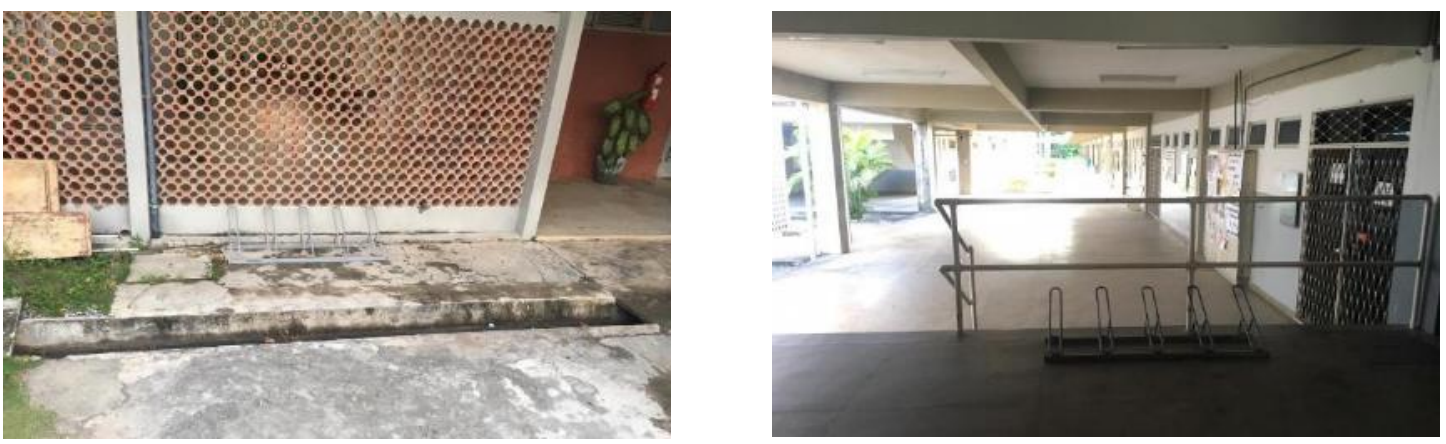

Fonte: Autores, 2019.

Figuras 13 e 14 - Bicicletas estacionadas em locais inadequados
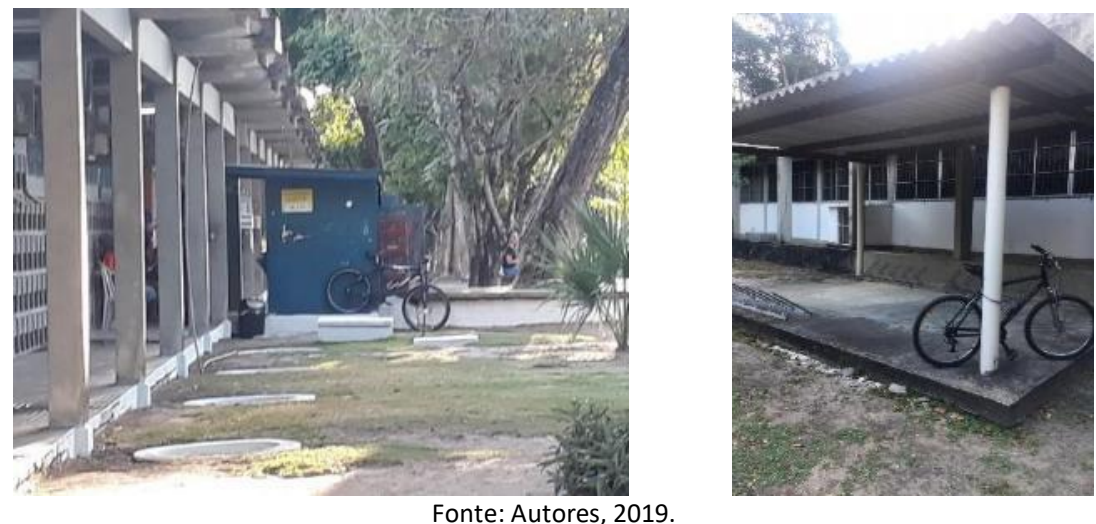

\section{CONSIDERAÇÕES FINAIS}

Com a demanda por mais qualidade de vida nas cidades, é interessante destacar a importância de se pensar em infraestrutura que facilite e propicie o uso de transportes alternativos como a bicicleta. Para tanto, a inserção de paraciclos que tenham design adequado em todo o campus I da UFPB é uma importante ação de incentivo e garantia de manutenção do uso desse tipo de modal na área de estudo.

A partir da aplicação do método e ferramentas apresentadas neste artigo, foi possível desenvolver aspectos para o idealizar o projeto e os requisitos para implantação de paraciclos na UFPB. A metodologia empregada se mostrou útil para a construção de um pensamento coletivo do grupo envolvido e formulação de diretrizes projetuais.

Além disso, o levantamento de dados e definição de elementos chave para o projeto, servem de base para estudos futuros de modo a evitar erros que já foram feitos, e ações de planejamento para a inserção de infraestrutura de transporte cicloviário no campus. Conclui-se, portanto, que a ferramenta testada e as etapas do GODP podem contribuir bastante para garantir o cumprimento das necessidades do usuário bem como guiar todo o processo de concepção em projetos arquitetônicos e de produtos. 


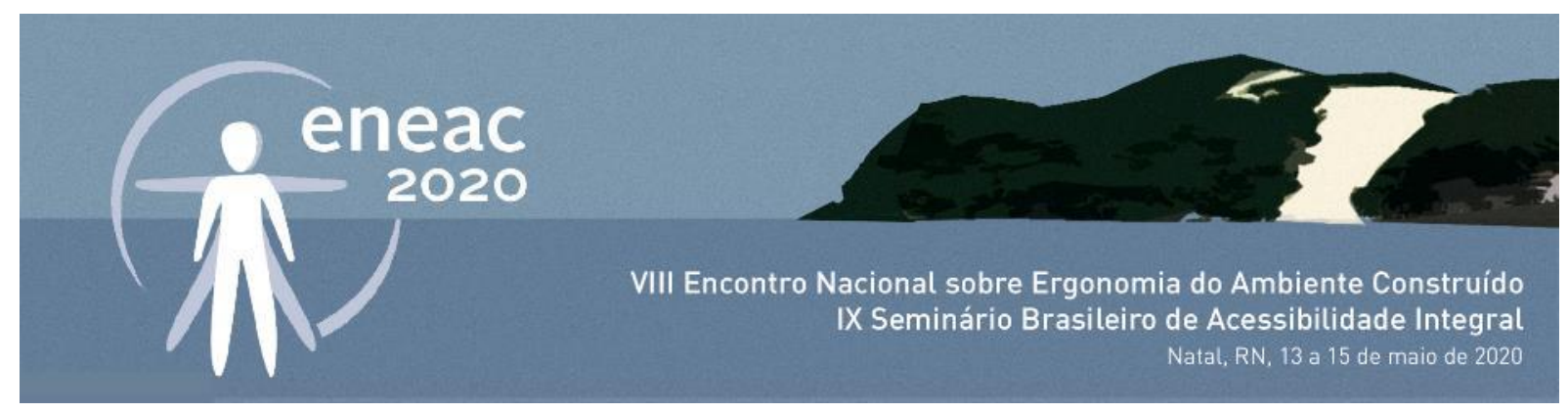

\section{REFERÊNCIAS}

ACBC, Associação de Ciclismo de Balneário Camboriú. Guia para construção de bicicletários adequados. Balneário Camboriú: ACBC, 2012.

ANDRADE, V., RODRIGUES, J., MARINO, F. e LOBO, Z. (Orgs.). Mobilidade por bicicleta no Brasil. 1. ed., Rio de Janeiro: PROURB/UFRJ, 2015.

CEVADA, C. M. Avaliação para uso da bicicleta: estudo de caso do Campus da UFPB e seu entorno imediato, Dissertação de mestrado, João Pessoa, PPGAU/UFPB, 2015.

HEINEN, E; BUEHLER, R. Bicycle parking: a systematic review of scientific literature on parking behaviour, parking preferences, and their influence on cycling and travel behaviour. Transport Reviews, 39(5), 630-656, 2019.

KHADEM, N. K. et al. Bike Station Suitability on University Campus Using Origin-Destination Matrix-A Morgan State University Case Study. Urban Science, v. 3, n. 3, p. 74, 2019.

LAWSON, B. Como arquitetos e designers pensam. São Paulo: Oficina de Textos, 2011.

MELO, A.; ABELHEIRA, R. Design thinking \& thinking design: metodologia, ferramentas e uma reflexão sobre o tema. São Paulo: Novatec, 2015.

MERINO, G. S. A. D. GODP - Guia de Orientação para Desenvolvimento de Projetos: Uma metodologia de Design Centrado no Usuário. Florianópolis: NGD/UFSC, 2016. Disponível em: www.ngd.ufsc.br. Acesso em: 12 nov. 2019.

RHEINGANTZ, P. A. et al. Observando a qualidade do lugar: procedimentos para a avaliação pós-ocupação. Rio de Janeiro: PROARQ/FAU-UFRJ, 2009.

TURNHOUT, K. V.; ANNEMA, J. H.; GOOR, J. V.; JACOBS, M.; BAKKER, R. Planning Spontaneity: A Case Study About Method Configuration. In: CHRISTENSEN, B. T.; BALL, L. J.; HALSKOV, K. (Orgs.). Analysing Design Thinking: Studies of CrossCultural Co-Creation. London, UK: Taylor \& Francis Group, 2017.

VELOSO, M.; ELALI, G. A. Projeto como construção coletiva: da participação à colaboração - os desafios do ensino. In: Encontro da Associação Nacional de Pesquisa e Pós-graduação em Arquitetura e Urbanismo - ENANPARQ, 3., 2014, São Paulo. Anais... São Paulo, 2014. 